\title{
DHA in Pregnant and Lactating Women from Coastland, Lakeland, and Inland Areas of China: Results of a DHA Evaluation in Women (DEW) Study
}

\author{
You Li ${ }^{1,2, \dagger}$, Hong-tian $\mathrm{Li}^{1,2, \dagger}$, Leonardo Trasande ${ }^{3}$, Hua Ge ${ }^{4}$, Li-xia Yu ${ }^{5}$, Gao-sheng $\mathrm{Xu}^{6}$, \\ Man-xi Bai ${ }^{7}$ and Jian-meng Liu ${ }^{1,2, *}$
}

Received: 13 August 2015 ; Accepted: 14 October 2015 ; Published: 21 October 2015

1 Institute of Reproductive and Child Health/Ministry of Health Key Laboratory of Reproductive Health, Peking University Health Science Center, 38 Xueyuan Rd, Beijing 100191, China; liyou@pku.edu.cn (Y.L.); liht@bjmu.edu.cn (H.L.)

2 Department of Epidemiology and Biostatistics, School of Public Health, Peking University Health Science Center, 38 Xueyuan Rd, Beijing 100191, China

3 Department of Pediatrics, NYU School of Medicine, 227 East 30th Street, Room 735, New York, NY 10016, USA; Leonardo.Trasande@nyumc.org

4 Department of Obstetrics and Gynaecology, the First Affiliated Hospital of Baotou Medical School, 41 Linyin Rd, Baotou 014000, China; byyfygh2010@163.com

5 Department of Obstetrics and Gynaecology, Weihai Maternal and Child Health Hospital, 51 Guangming Rd, Weihai 264200, China; whyulixia@126.com

6 Department of Pediatrics, Yueyang Maternal and Child Health Hospital, 693 Baling Middle Rd, Yueyang 414000, China; xugaosheng0414@163.com

7 Wyeth Nutrition Science Center, 582 Wuzhong Rd, Shanghai 201103, China;

Manxi.Bai@wyethnutrition.com

* Correspondence: liujm@pku.edu.cn; Tel.: +86-10-8280-1136; Fax: +86-10-8280-1141

$\dagger$ These authors contributed equally to this work.

\begin{abstract}
Few studies have examined docosahexaenoic acid (DHA) in pregnant and lactating women in developing countries like China, where DHA-enriched supplements are increasingly popular. We aimed to assess the DHA status among Chinese pregnant and lactating women residing areas differing in the availability of aquatic products. In total, 1211 women in mid-pregnancy (17 \pm 2 weeks), late pregnancy ( $39 \pm 2$ weeks), or lactation (42 \pm 7 days) were enrolled from Weihai (coastland), Yueyang (lakeland), and Baotou (inland) city, with approximately 135 women in each participant group by region. DHA concentrations were measured using capillary gas chromatography, and are reported as weight percent of total fatty acids. Mean plasma DHA concentrations were higher in coastland (mid-pregnancy 3.19\%, late pregnancy $2.54 \%$, lactation $2.24 \%)$ and lakeland women $(2.45 \%, 1.95 \%, 2.26 \%)$ than inland women $(2.25 \%, 1.67 \%, 1.68 \%)$ ( $p$ values $<0.001$ ). Similar differences were observed for erythrocyte DHA. We conclude that DHA concentrations of Chinese pregnant and lactating women are higher in coastland and lakeland regions than in inland areas. DHA status in the study population appears to be stronger than populations from other countries studied to date.
\end{abstract}

Keywords: docosahexaenoic acid; pregnant women; lactating women; plasma; erythrocyte; correlation

\section{Introduction}

Docosahexaenoic acid (DHA, 22:6n-3), as a fundamental constituent in cell membranes, is indispensable to the structure and function of the retina and central nervous system [1,2]. DHA is mainly contained in aquatic products, especially in seafood. Dietary DHA intake is a major 
source to meet human body requirements, since humans only synthesize a limited amount of DHA from $\alpha$-linolenic acid [3]. It is widely acknowledged that pregnant and lactating women are more susceptible to DHA deficiency because they need to meet their own needs as well as those of the fetuses. Increased intake of DHA during pregnancy and lactation has been documented to benefit fetal and infant development [4-7].

The availability and consumption of aquatic products plays an important role in DHA status. In a study [8] conducted among women from four Tanzanian tribes differing in lifetime intakes of fish, Luxwolda et al. observed an obvious positive correlation between fish consumption and DHA levels. DHA status may also vary across ethnicities. In a study [9] comparing plasma DHA phospholipids between Dutch and ethnic minority pregnant women in Netherlands, van Eijsden et al. reported significant ethnic differences in maternal DHA status despite controlling for fish intake. Besides, in an earlier study [10] involving women from Ecuador and four European countries with different baseline phospholipid DHA status, Otto et al. observed consistent decreases in the DHA weight percentage of total fatty acids as women progress from early pregnancy to delivery.

In China, fish availability varies considerably in populations, and is greatest in coastland and lakeland regions in contrast to inland areas. In this study, we aimed to examine DHA status in a diverse population of Chinese pregnant and lactating women from coastland, lakeland, and inland areas.

\section{Subjects and Methods}

\subsection{Settings and Subjects}

The DHA Evaluation in Women (DEW) study was a cross-sectional survey conducted from May to July 2014 in three cities of China: Weihai (selected to represent the coastland population), Yueyang (selected to represent the lakeland population) and Baotou (selected to represent the inland population). Weihai is surrounded on three sides by the Huang Sea. Yueyang is near Dongting Lake, the second largest freshwater lake in China. Baotou is a typical inland city in the Mongolian Plateau. A total of 1211 apparently healthy women who were at mid-pregnancy (17 \pm 2 gestational weeks), late pregnancy (39 \pm 2 gestational weeks), or lactation (42 \pm 7 days postpartum) were recruited approximately equally from the three regions, with on average 135 (127-138) women in each group per region. Eligible women were 18-35 years old, were local permanent residents, and had singleton pregnancies. An additional inclusion criterion for the lactating group was current breastfeeding. Women were excluded if they had been diagnosed with any cardiovascular, metabolic, and renal diseases, mental disorder, or aquatic food allergy; or had participated in other research projects in the past 30 days. Women with severe vomiting after 16 weeks of gestation were also excluded for the mid-pregnancy group. The research protocol was approved by the Institutional Review Boards/Human Subjects Committees at Peking University Health Science Center (IRB00001052-14012; date of approval: 22-04-2014), and all participating women signed informed consents.

\subsection{Data and Sample Collection}

Participants were enrolled from four local hospitals: one located in Weihai, one in Yueyang, and two in Baotou. Trained obstetricians or nurses from the hospitals completed enrolment and data collection. A structured questionnaire was used to collect maternal characteristics, including birthdate, ethnicity, height, pre-pregnancy weight, and educational attainment. For pregnant women, gestational age at enrolment was calculated according to the date of the last menstrual period. For lactating women, self-reported gestational age at delivery and parity were also collected.

Fasting venous blood $(\sim 5 \mathrm{~mL})$ was collected from the antecubital vein into ethylenediaminetetraacetic acid (EDTA)-containing tubes. Samples were kept in the refrigerator at $5{ }^{\circ} \mathrm{C}$ for at least $30 \mathrm{~min}$ and then centrifuged at $3000 \times \mathrm{g}$ for $10 \mathrm{~min}$ to separate plasma and 
erythrocytes. The erythrocytes were washed out with normal saline. Both plasma and erythrocyte samples were stored at $-20^{\circ} \mathrm{C}$ in the hospital for approximately 10 days, and then were transported on dry ice frozen at $-80^{\circ} \mathrm{C}$ to the central laboratory where samples were stored at a $-80^{\circ} \mathrm{C}$ freezer. Notably, the temporal storage of blood samples at $-20^{\circ} \mathrm{C}$ might have somewhat compromised DHA in erythrocyte [11,12].

To ensure data quality and to standardize data collection methodologies across sites, study staff attended training workshops and each site had a designated investigator who oversaw the standardized data collection procedures. In addition, senior investigators met weekly and provided additional oversight.

\subsection{Sample Analysis}

The extraction and derivatization of total lipids in plasma and erythrocyte samples were carried out using a modified method of Folch et al. [13]. The internal standard solution containing methyl undecanoate (C11:0) was added to the samples, and mixed with boron trifluoride and methanol. This mixture was heated at $115{ }^{\circ} \mathrm{C}$ for $20 \mathrm{~min}$. After cooling to room temperature, the mixture was extracted with n-hexane. The n-hexane containing methyl esters of total lipids were analyzed by an Agilent $6890 \mathrm{~N}$ gas chromatography (Agilent Technologies, Palo Alto, CA, USA) equipped with a flame ionization detector at $280{ }^{\circ} \mathrm{C}$ and a capillary column (CP-Sil $88,50 \mathrm{~m}, 0.25 \mathrm{~mm}$ ID, $0.20 \mu \mathrm{m}$ film thickness). The injector was set as a split mode at $250{ }^{\circ} \mathrm{C}$, with the split ratio of 1:5. The oven temperature was programmed as follows: ramping from $120^{\circ} \mathrm{C}$ to $166^{\circ} \mathrm{C}$ at $2{ }^{\circ} \mathrm{C} / \mathrm{min}$, and holding at $166{ }^{\circ} \mathrm{C}$ for $10 \mathrm{~min}$; then ramping to $200{ }^{\circ} \mathrm{C}$ at $2{ }^{\circ} \mathrm{C} / \mathrm{min}$ and holding at $200{ }^{\circ} \mathrm{C}$ for $10 \mathrm{~min}$. Individual fatty acids were identified against the reference standards. The data were collected and processed using Agilent OpenLAB software (Agilent Technologies, Santa Clara, CA, USA). Both absolute concentration $(\mu \mathrm{g} / \mathrm{mL})$ and the relative concentration (weight percent of total fatty acids, wt. \%) of DHA were calculated.

\subsection{Statistical Analysis}

DHA concentrations are presented as means \pm SDs. One-way analyses of variance were performed to compare overall differences in DHA concentrations among participant groups and regions. T-tests were used to examine the differences between women in inland and lakeland/coastland as well as between women in mid-pregnancy and late-pregnancy/lactation. Additionally, we explored whether DHA concentrations varied across subgroups based on maternal age (18.0-24.9, 25.0-29.9, and 30.0-34.9 years), pre-pregnancy BMI $(<18.5,18.5-23.9$, and $\geqslant 24.0 \mathrm{~kg} / \mathrm{m}^{2}$ ), and education attainment (middle school or less, high school, and college or above) by using multiple linear regression with adjustments for covariates including region and participant group.

To illustrate the relationship between plasma and erythrocyte DHA, we performed several sets of Pearson correlation analyses. We first estimated the overall correlation coefficient between plasma and erythrocyte relative DHA concentrations. Because the scatterplot indicated an obviously different correlation pattern between individuals with erythrocyte DHA concentrations $\geqslant 3 \%$ and those $<3 \%$, separate correlation analyses for the two subgroups were then performed. We also repeated the above-mentioned correlation analyses within the 9 subgroups defined by region and participant group.

Significance was set at $p<0.05$. All statistical analyses were performed by using SPSS version 20.0 (Chicago, IL, USA). 


\section{Results}

\subsection{Maternal Characteristics}

Table 1 shows maternal characteristics by region and participant group. Overall, $87.8 \%$ women had high school or above education. In coastland and lakeland populations, $98.0 \%$ were of Han ethnicity, whereas the percentage was somewhat lower $(89.8 \%)$ in inland, where $7.1 \%$ were Mongolian. The mean age, height, and pre-pregnancy BMI were comparable for the three participant groups residing coastland and inland, whereas women from the lakeland were younger, shorter in stature, and had lower pre-pregnancy BMI ( $p$ values $<0.001)$. In the lactating group, primiparous women accounted for $87.5 \%, 81.5 \%$, and $86.0 \%$ in coastland, lakeland, and inland, respectively, and corresponding mean gestational age at delivery in the three regions was 39.3, 39.3, and 39.1 weeks, respectively.

Table 1. Maternal characteristics by region and participant group.

\begin{tabular}{|c|c|c|c|c|c|c|c|c|c|}
\hline \multirow[b]{2}{*}{ Characteristic } & \multicolumn{3}{|c|}{ Coastland } & \multicolumn{3}{|c|}{ Lakeland } & \multicolumn{3}{|c|}{ Inland } \\
\hline & MP & LP & LA & MP & LP & LA & MP & LP & LA \\
\hline Number of participants & 136 & 127 & 136 & 133 & 134 & 135 & 138 & 136 & 136 \\
\hline \multicolumn{10}{|c|}{ GA (week)/PP (day) at enrolment } \\
\hline Mean & 16.9 & 37.5 & 42.7 & 17.0 & 38.0 & 41.7 & 16.7 & 38.6 & 42.1 \\
\hline $\mathrm{SD}$ & 0.9 & 0.7 & 2.3 & 1.1 & 0.9 & 4.1 & 1.1 & 1.2 & 3.9 \\
\hline \multicolumn{10}{|l|}{ Age (year) } \\
\hline Mean & 27.9 & 28.4 & 28.3 & 26.5 & 27.1 & 27.1 & 27.9 & 28.5 & 28.1 \\
\hline SD & 2.4 & 2.7 & 2.7 & 3.1 & 3.1 & 3.0 & 2.9 & 3.3 & 3.0 \\
\hline \multicolumn{10}{|l|}{ Ethnics (\%) } \\
\hline Han & 97.8 & 99.2 & 97.1 & 98.5 & 97.8 & 97.8 & 83.3 & 94.1 & 91.9 \\
\hline Mongolian & 0 & 0 & 0 & 0 & 0 & 0 & 12.3 & 4.4 & 4.4 \\
\hline Hui & 0 & 0 & 0.7 & 0 & 0 & 0 & 0.7 & 0.7 & 2.2 \\
\hline Others & 2.2 & 0.8 & 2.2 & 1.5 & 2.2 & 2.2 & 3.6 & 0.7 & 1.5 \\
\hline \multicolumn{10}{|l|}{ Education (\%) } \\
\hline College or above & 67.7 & 66.2 & 65.4 & 47.4 & 61.3 & 62.2 & 79.0 & 78.4 & 73.5 \\
\hline High school & 15.4 & 24.4 & 25.0 & 36.8 & 24.6 & 23.7 & 13.8 & 16.2 & 19.1 \\
\hline Middle school or less & 16.9 & 9.4 & 9.6 & 15.8 & 14.1 & 14.1 & 7.2 & 15.4 & 7.4 \\
\hline \multicolumn{10}{|l|}{ Height $(\mathrm{cm})$} \\
\hline Mean & 163.6 & 163.7 & 163.2 & 159.3 & 159.8 & 159.8 & 164.1 & 162.8 & 163.1 \\
\hline SD & 4.9 & 4.6 & 5.0 & 4.5 & 3.9 & 4.3 & 4.9 & 4.7 & 4.6 \\
\hline \multicolumn{10}{|l|}{ Pre-pregnancy BMI $\left(\mathrm{kg} / \mathrm{m}^{2}\right)$} \\
\hline Mean & 21.1 & 21.3 & 21.9 & 20.2 & 19.8 & 20.1 & 21.3 & 21.6 & 21.2 \\
\hline SD & 2.8 & 2.5 & 3.5 & 2.5 & 1.9 & 2.9 & 3.3 & 2.8 & 3.2 \\
\hline
\end{tabular}

GA, gestational age; PP, postpartum; MP, mid-pregnancy; LP, late pregnancy; LA, lactation.

\subsection{DHA Concentrations}

Mean plasma and erythrocyte relative DHA concentrations of 9 region- and group-specific subgroups ranged $1.67 \%-3.19 \%$ and $5.06 \%-7.59 \%$, respectively; corresponding absolute values ranged between 60.5 and $146.2 \mu \mathrm{g} / \mathrm{mL}$ and $89.3-127.7 \mu \mathrm{g} / \mathrm{mL}$, respectively (Table 2). 
Table 2. Docosahexaenoic acid (DHA) concentrations by region and participant group.

\begin{tabular}{|c|c|c|c|c|c|c|c|}
\hline & \multicolumn{2}{|c|}{ Inland } & \multicolumn{2}{|c|}{ Lakeland } & \multicolumn{2}{|c|}{ Coastland } & \multirow{2}{*}{$P$ ANOVA } \\
\hline & Mean & SD & Mean & SD & Mean & SD & \\
\hline \multicolumn{8}{|l|}{ wt. \% } \\
\hline $\begin{array}{c}\text { Plasma } \\
\text { Mid-pregnancy }\end{array}$ & 2.25 & 0.46 & $2.45^{\mathrm{a}}$ & 0.44 & $3.19^{\mathrm{a}}$ & 0.65 & $<0.001$ \\
\hline $\begin{array}{l}\text { Late } \\
\text { preonancy }\end{array}$ & $1.67^{\mathrm{b}}$ & 0.35 & $1.95^{\mathrm{a}, \mathrm{b}}$ & 0.45 & $2.54^{\mathrm{a}, \mathrm{b}}$ & 0.60 & $<0.001$ \\
\hline Lactation & $1.68^{b}$ & 0.48 & $2.26^{\mathrm{a}, \mathrm{b}}$ & 0.53 & $2.24^{\mathrm{a}, \mathrm{b}}$ & 0.70 & $<0.001$ \\
\hline$P$ ANOVA & \multicolumn{2}{|c|}{$<0.001$} & \multicolumn{2}{|c|}{$<0.001$} & \multirow{2}{*}{\multicolumn{2}{|c|}{$<0.001$}} & \\
\hline Erythrocyte & & & & & & & \\
\hline \multirow{2}{*}{$\begin{array}{l}\text { Mid-pregnancy } \\
\text { Late } \\
\text { pregnancy }\end{array}$} & 5.85 & 1.06 & $6.34^{\mathrm{a}}$ & 0.80 & $7.59^{\mathrm{a}}$ & 1.46 & $<0.001$ \\
\hline & $5.06^{b}$ & 1.25 & $6.23^{\mathrm{a}}$ & 1.09 & $7.09^{a, b}$ & 1.93 & $<0.001$ \\
\hline Lactation & $5.20^{b}$ & 1.15 & $6.20^{\mathrm{a}}$ & 0.92 & $6.07^{a, b}$ & 1.59 & $<0.001$ \\
\hline $\begin{array}{l}P \text { ANOVA } \\
\mu \mathrm{g} / \mathrm{mL} \\
\text { Plasma }\end{array}$ & \multicolumn{2}{|c|}{$<0.001$} & \multicolumn{2}{|c|}{0.45} & \multicolumn{2}{|c|}{$<0.001$} & \\
\hline \multirow{2}{*}{$\begin{array}{c}\text { Mid-pregnancy } \\
\text { Late } \\
\text { pregnancy }\end{array}$} & 93.4 & 25.2 & \multirow{2}{*}{$\begin{array}{c}86.2^{\mathrm{a}} \\
110.1 \\
\mathrm{a}, \mathrm{b}\end{array}$} & 20.5 & \multirow{2}{*}{$\begin{array}{c}118.4^{a} \\
146.2 \\
a, b\end{array}$} & 30.8 & $<0.001$ \\
\hline & $101.9^{b}$ & 33.1 & & 28.3 & & 45.1 & $<0.001$ \\
\hline Lactation & $60.5^{b}$ & 17.5 & $65.1^{\mathrm{b}}$ & 20.9 & $75.7^{a, b}$ & 29.9 & $<0.001$ \\
\hline$P$ ANOVA & \multicolumn{2}{|c|}{$<0.001$} & \multicolumn{2}{|c|}{$<0.001$} & \multicolumn{2}{|c|}{$<0.001$} & \\
\hline \multirow{4}{*}{$\begin{array}{c}\text { Mid-pregnancy } \\
\text { Late } \\
\text { pregnancy } \\
\text { Lactation } \\
\text { P ANOVA }\end{array}$} & 108.0 & 22.1 & $103.2^{\mathrm{a}}$ & 13.6 & $127.7^{\mathrm{a}}$ & 27.2 & $<0.001$ \\
\hline & $89.3^{b}$ & 25.2 & $106.6^{\mathrm{a}}$ & 20.7 & $123.2^{\mathrm{a}}$ & 37.5 & $<0.001$ \\
\hline & $91.4^{\mathrm{b}}$ & 22.1 & $97.0^{\mathrm{a}, \mathrm{b}}$ & 19.7 & $99.3^{a, b}$ & 29.6 & $<0.05$ \\
\hline & \multicolumn{2}{|c|}{$<0.001$} & \multicolumn{2}{|c|}{$<0.001$} & \multicolumn{2}{|c|}{$<0.001$} & \\
\hline
\end{tabular}

ANOVA, analyses of variance. ${ }^{a}$ : Mean values were significant different compared with women from inland within the same participant group (by $t$-test, $p<0.05$ ); ${ }^{\text {b }}$ : mean values were significant different compared with women in mid-pregnancy within the same region (by $t$-test).

Plasma and erythrocyte DHA relative concentrations differed by region across participant groups ( $p$ values $<0.001$ ). The concentrations were higher in coastland and lakeland women than in inland women. Similar regional differences in DHA absolute concentrations were observed (Table 2).

Plasma DHA relative concentrations differed significantly by participant groups across the regions ( $p$ values $<0.001$ ); the concentrations were higher in mid-pregnancy than in late pregnancy and lactating women across regions $(p$ values $<0.001)$. Similar patterns were also observed for erythrocyte DHA relative concentrations, although the difference was not significant among the three groups of lakeland women. In contrast, the plasma DHA absolute concentrations were highest in late-pregnancy women, followed by in mid-pregnancy, and lowest in lactating women. The erythrocyte DHA absolute concentrations were relatively higher in mid-pregnancy in inland, in midand late-pregnancy in lakeland and coastland women (Table 2).

In multiple linear regression analyses, maternal age and education were significantly associated with DHA concentrations; patterns for regional and inter-group DHA were similar to the aforementioned unadjusted analyses (Table 3).

\subsection{Correlation between DHA in Plasma and Erythrocyte}

The overall Pearson correlation coefficient between plasma and erythrocyte relative DHA concentrations was $0.625(p<0.001)$. The correlation profile was visually examined via a scatterplot and an obviously different correlation pattern was detected between women with erythrocyte DHA concentration $\geqslant 3 \%$ and those $<3 \%$ (Figure 1). The significant positive correlation persisted only in women with erythrocyte DHA concentrations $\geqslant 3 \%(n=1175 ; r=0.73, p<0.001)$, but not in those $<3 \%(n=36 ; r=-0.13, p=0.46)$. After excluding women with erythrocyte DHA concentrations $<3 \%$, most of region- and group-specific correlation coefficients were substantially augmented by $18 \%-64 \%$ (Supplementary Table S1). 
Table 3. Multiple linear regression of DHA concentrations on region, participant group and selected maternal characteristics.

\begin{tabular}{|c|c|c|c|c|c|c|c|c|c|c|c|c|}
\hline \multirow{2}{*}{ Variables } & \multicolumn{3}{|c|}{ Plasma DHA (wt. \%) } & \multicolumn{3}{|c|}{ Erythrocyte DHA (wt. \%) } & \multicolumn{3}{|c|}{ Plasma DHA $(\mu \mathrm{g} / \mathrm{mL})$} & \multicolumn{3}{|c|}{ Erythrocyte DHA $(\mu \mathrm{g} / \mathrm{mL})$} \\
\hline & Mean & $\beta$ & $P$ & Mean & $\beta$ & $P$ & Mean & $\beta$ & $P$ & Mean & $\beta$ & $P$ \\
\hline Region & & & & & & & & & & & & \\
\hline Inland & 1.87 & 0 & Ref. & 5.37 & 0 & Ref. & 85.3 & 0 & Ref. & 96.3 & 0 & Ref. \\
\hline Lakeland & 2.22 & 0.36 & $<0.001$ & 6.25 & 0.92 & $<0.001$ & 87.0 & 3.6 & 0.091 & 102.2 & 6.7 & $<0.001$ \\
\hline Coastland & 2.66 & 0.80 & $<0.001$ & 6.91 & 1.55 & $<0.001$ & 112.7 & 28.4 & $<0.001$ & 116.6 & 20.4 & $<0.001$ \\
\hline \multicolumn{13}{|l|}{ Participant group } \\
\hline Mid-pregnancy & 2.63 & 0 & Ref. & 6.59 & 0 & Ref. & 99.4 & 0 & Ref. & 113.0 & 0 & Ref. \\
\hline Late pregnancy & 2.04 & -0.59 & $<0.001$ & 6.10 & -0.49 & $<0.001$ & 118.8 & 19.4 & $<0.001$ & 106.0 & -7.0 & $<0.001$ \\
\hline Lactation & 2.06 & -0.58 & $<0.001$ & 5.82 & -0.79 & $<0.001$ & 67.1 & -32.9 & $<0.001$ & 95.9 & -17.5 & $<0.001$ \\
\hline \multicolumn{13}{|l|}{ Age(year) } \\
\hline$<25.0$ & 2.15 & 0 & Ref. & 5.93 & 0 & Ref. & 88.2 & 0 & Ref. & 100.2 & 0 & Ref. \\
\hline $25.0-29.9$ & 2.27 & 0.02 & 0.623 & 6.24 & 0.17 & 0.129 & 94.7 & 1.7 & 0.499 & 106.1 & 2.8 & 0.191 \\
\hline$\geqslant 30.0$ & 2.25 & 0.12 & 0.029 & 6.15 & 0.25 & 0.050 & 100.6 & 7.9 & 0.006 & 105.3 & 4.0 & 0.108 \\
\hline \multicolumn{13}{|l|}{ Education } \\
\hline Middle school or less & 2.18 & 0 & Ref. & 5.93 & 0 & Ref. & 90.1 & 0 & Ref. & 100.2 & 0 & Ref. \\
\hline High school & 2.24 & 0.07 & 0.187 & 6.20 & 0.29 & 0.033 & 94.2 & 7.2 & 0.016 & 105.0 & 5.6 & 0.034 \\
\hline College or above & 2.26 & 0.12 & 0.014 & 6.21 & 0.36 & 0.003 & 96.0 & 8.5 & 0.002 & 105.8 & 6.4 & 0.006 \\
\hline \multicolumn{13}{|l|}{ Pre-pregnancy BMI } \\
\hline$<18.5$ & 2.26 & 0 & Ref. & 6.15 & 0 & Ref. & 90.7 & 0 & Ref. & 103.0 & 0 & Ref. \\
\hline $18.5-23.9$ & 2.27 & -0.07 & 0.073 & 6.22 & -0.06 & 0.546 & 96.0 & -0.3 & 0.901 & 105.9 & 0.1 & 0.970 \\
\hline$\geqslant 24.0$ & 2.12 & -0.21 & $<0.001$ & 5.97 & -0.20 & 0.143 & 95.3 & 1.6 & 0.612 & 103.2 & -1.7 & 0.523 \\
\hline
\end{tabular}

$\beta$, regression coefficient; Ref, reference category. 


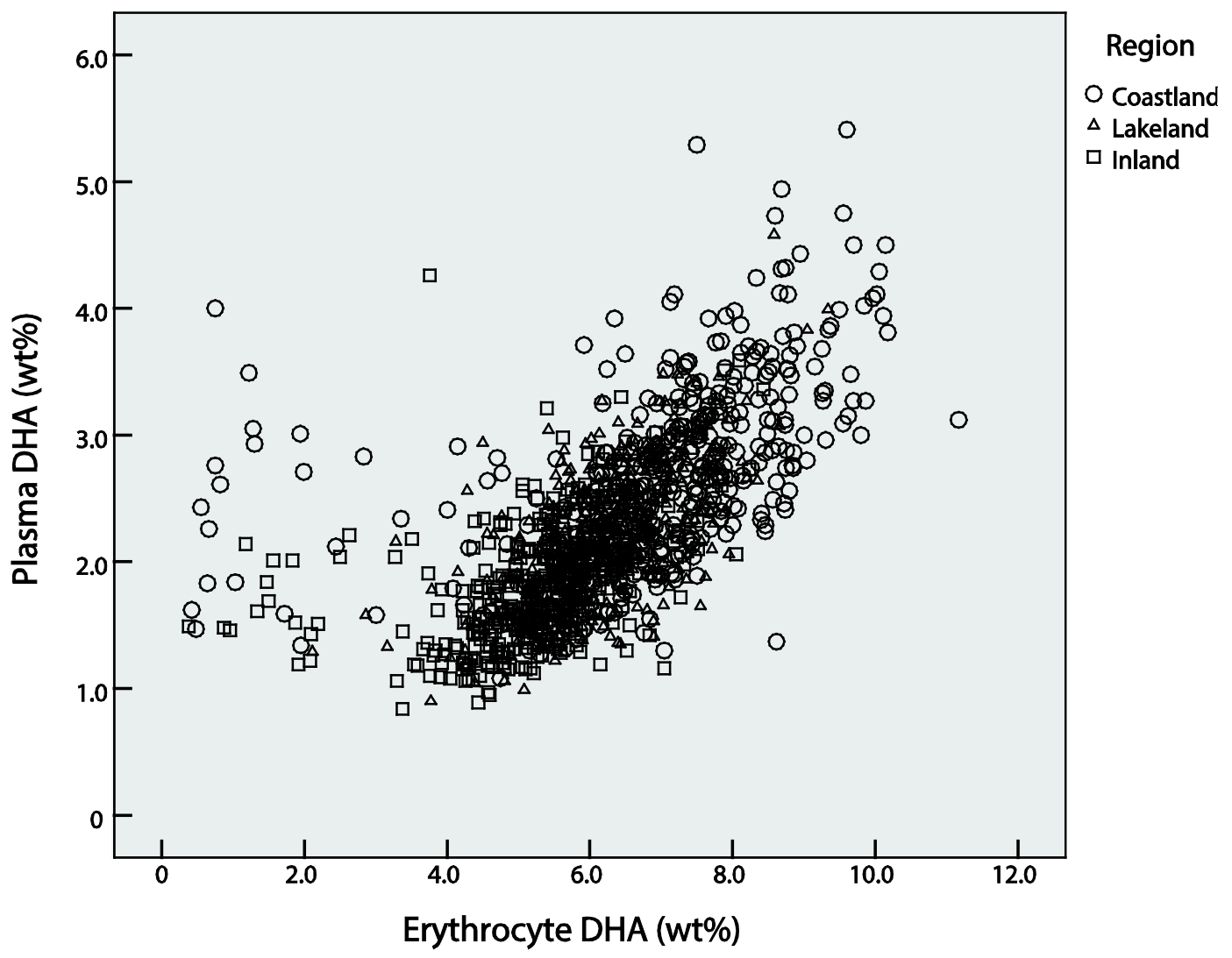

Figure 1. Correlation between plasma and erythrocyte DHA relative concentrations in 1211 participants.

\section{Discussion}

In this large cross-sectional study conducted in three typical urban areas of China, DHA concentrations measured by relative weight percent to total fatty acids in pregnant and lactating women were higher in coastland/lakeland women than in inland women as well as higher in mid-pregnancy than in late-pregnancy/lactation. Moreover, we observed a moderate to high degree of correlation between plasma and erythrocyte DHA.

Consistent with a previous study [8], we found DHA concentrations, whether in plasma or erythrocyte, for each participant group, were significantly higher in coastland/lakeland than in inland women, likely reflecting differences in consuming aquatic products. Relevant data of Chinese pregnant or lactating women are sparse. One small study [14] conducted in 138 late-pregnant Chinese women reported similar results for plasma choline phosphoglyceride DHA: highest in coastland, followed by lakeland, and lowest in inland. In addition, consistent with longitudinal studies [10,15], we observed that both plasma and erythrocyte DHA relative concentrations, despite the region, were significantly higher in mid-pregnancy than in late-pregnancy, probably in response to an increasing fetal needs for DHA and an increasing blood volume during pregnancy [16,17]. Meanwhile, we noticed that DHA absolute concentrations were higher in late-pregnancy than mid-pregnancy, which was probably due to an increasing synthesis during pregnancy [17]. Additionally, consistent with the findings from Stark et al. [18], DHA concentrations in plasma and erythrocytes increased with maternal age and education, possibly reflecting the difference in consuming aquatic products. We further compared DHA concentrations in total lipids (reported as wt. \% of total fatty acids) with other populations worldwide, and found that the DHA concentrations of Chinese pregnant and lactating women were at relatively high level. Specifically, the concentrations of our inland women were higher than those of women residing in inland areas of India [19] or Germany [20], and close to or even higher than those of women residing in coastal areas of some nations like USA, United Kingdom, 
Denmark, Norway, Japan, or Canada [17,21-25]; however, the concentrations of our coastland women were slightly lower than those of Spanish (mid-pregnancy: 3.19\% versus 3.70\% in plasma) [26] and Cubans (lactation: $2.24 \%$ versus $2.56 \%$ in plasma and $6.07 \%$ versus $6.80 \%$ in erythrocyte) [27]. Besides differences in consuming aquatic products or DHA enriched supplements, the potential explanations for ethnic differences also involve DHA synthesis and metabolism, for FADS genotypes influence maternal DHA concentrations [28,29].

As expected, we observed a moderate to high level of positive correlation between plasma and erythrocyte DHA (Pearson's $r=0.63)$. The correlation was even stronger $(r=0.73)$ in women with erythrocyte DHA $\geqslant 3 \%$, but not at all in those with erythrocyte DHA $<3 \%(n=36 ; r=-0.13$, $p=0.46)$; interestingly, the plasma concentrations in the two subgroups of women $(2.25 \%$ versus $2.04 \%$ ) did not differ materially. One explanation regarding the inflection point in the correlation between plasma and erythrocyte DHA was that erythrocyte could serve as a reservoir and its DHA could be transported into plasma for body need in case of a lower DHA status [30]. Another explanation was that the storage of the blood samples at $-20{ }^{\circ} \mathrm{C}$ might have compromised erythrocyte DHA, especially in those with lower DHA concentrations, whereas the storage probably had no impact on plasma DHA, which in turn resulted in a flawed deviation from the linear correlation [11,12]. Therefore, the correlation identified in our study should be interpreted with caution, which remains to be confirmed in further studies.

Our study has multiple strengths. We selected three typical regions with plausible differences in DHA intake due to differences in the availability of aquatic products, and recruited three groups of women to simultaneously assess DHA status in mid-pregnant, late-pregnant and lactating women by region. Procedures in data collection and sample analyses were intensively monitored. The region- and participant group-specified sample size ( 135) was the largest compared to previous similar studies $(\sim 50)$. However, our study also has several limitations. Firstly, the study was not longitudinal, and was conducted only in urban areas of China, possibly confining the generalization of findings. Secondly, the mean erythrocyte DHA concentrations might be slightly lower than the true values due to the temporary storage of blood samples under $-20{ }^{\circ} \mathrm{C}[11,12]$. Thirdly, the regional differences in DHA concentrations for pregnant and lactating women could not be simply generalized to the non-pregnant because the increased DHA synthesis during pregnancy was likely more pronounced in individuals with lower DHA intakes [17]. Additionally, we only focused on DHA in this study as a preliminary step to understand maternal status of polyunsaturated fatty acids (PUFAs) in our population. Further studies regarding other PUFAs are encouraged, which are critical to the understanding of the entire profile of PUFAs as well as its relationship with dietary fatty acids.

In summary, DHA concentrations of Chinese pregnant and lactating women are higher in coastland and lakeland regions than in inland areas. DHA status in our population appears to be stronger than populations from other countries as reported in the literature. DHA concentrations varied by region and participant groups, which is likely due to differences in consumption of aquatic products or changes in physiological needs for DHA.

Supplementary Materials: Supplementary materials can be accessed at: http://www.mdpi.com/2072-6643/ $7 / 10 / 5428 /$ s1.

Acknowledgments: The study was supported by a grant from Wyeth Nutrition Science Center (Project Number: 14.10.CN.INF). We thank all participants for their cooperation. We thank the dozens of physicians or nurses from Weihai Maternal and Child Health Hospital, Yueyang Maternal and Child Health Hospital, The First Affiliated Hospital of Baotou Medical School, and The Third Hospital of Baogang Group for their field work. We thank Lin-lin Wang, Ya-li Zhang, Zhao-xia Xiong, Yu-bo Zhou, and Meng-jiao Liu at the Peking University Institute of Reproductive and Child Health for their works on the project.

Author Contributions: The authors' responsibilities were as follows-Jian-meng Liu, Hong-tian Li and Man-xi Bai conceived and designed the study; Jian-meng Liu, Hong-tian Li, You Li, Hua Ge, Li-xia Yu, and Gao-sheng $\mathrm{Xu}$ conducted the field work; You Li and Hong-tian Li analyzed data; You Li, Hong-tian Li and Jian-meng Liu drafted the manuscript; Hong-tian Li, Jian-meng Liu, Leonardo Trasande and Man-xi Bai made critical reviews and revisions; All authors have reviewed and approved the final manuscript. Jian-meng Liu had primary responsibility for final content. 
Conflicts of Interest: Jian-meng Liu has received a grant from Wyeth Nutrition Science Center and presented the part of the results at a scientific workshop organized by Wyeth Nutrition Science Center. Man-xi Bai is working for Wyeth Nutrition Science Center. All other authors declared no conflict of interest.

\section{References}

1. Heird, W.C.; Lapillonne, A. The role of essential fatty acids in development. Ann. Rev. Nutr. 2005, 25, 549-571. [CrossRef] [PubMed]

2. Lauritzen, L.; Hansen, H.S.; Jorgensen, M.H.; Michaelsen, K.F. The essentiality of long chain $n-3$ fatty acids in relation to development and function of the brain and retina. Prog. Lipid Res. 2001, 40,1-94. [CrossRef]

3. FAO. Fats and Fatty Acids in Human Nutrition; Report of an Expert Consultation; Karger: Basel, Switzerland, 2010; Volume 91, pp. 1-166.

4. Carlson, S.E.; Colombo, J.; Gajewski, B.J.; Gustafson, K.M.; Mundy, D.; Yeast, J.; Georgieff, M.K.; Markley, L.A.; Kerling, E.H.; Shaddy, D.J.; et al. DHA supplementation and pregnancy outcomes. Am. J. Clin. Nutr. 2013, 97, 808-815. [CrossRef] [PubMed]

5. Hibbeln, J.R.; Davis, J.M.; Steer, C.; Emmett, P.; Rogers, I.; Williams, C.; Golding, J. Maternal seafood consumption in pregnancy and neurodevelopmental outcomes in childhood (ALSPAC study): An observational cohort study. Lancet 2007, 369, 578-585. [CrossRef]

6. Makrides, M.; Gibson, R.A.; McPhee, A.J.; Yelland, L.; Quinlivan, J.; Ryan, P.; Team, D.O.I. Effect of DHA supplementation during pregnancy on maternal depression and neurodevelopment of young children: A randomized controlled trial. JAMA 2010, 304, 1675-1683. [CrossRef] [PubMed]

7. Muthayya, S.; Dwarkanath, P.; Thomas, T.; Ramprakash, S.; Mehra, R.; Mhaskar, A.; Mhaskar, R.; Thomas, A.; Bhat, S.; Vaz, M.; et al. The effect of fish and omega-3 LCPUFA intake on low birth weight in Indian pregnant women. Eur. J. Clin. Nutr. 2009, 63, 340-346. [CrossRef] [PubMed]

8. Luxwolda, M.F.; Kuipers, R.S.; Koops, J.H.; Muller, S.; de Graaf, D.; Dijck-Brouwer, D.A.; Muskiet, F.A. Interrelationships between maternal DHA in erythrocytes, milk and adipose tissue. Is 1 wt \% DHA the optimal human milk content? Data from four tanzanian tribes differing in lifetime stable intakes of fish. Br. J. Nutr. 2014, 111, 854-866. [CrossRef] [PubMed]

9. Van Eijsden, M.; Hornstra, G.; van der Wal, M.F.; Bonsel, G.J. Ethnic differences in early pregnancy maternal n-3 and n-6 fatty acid concentrations: An explorative analysis. Br. J. Nutr. 2009, 101, 1761-1768. [CrossRef] [PubMed]

10. Otto, S.J.; Houwelingen, A.C.; Antal, M.; Manninen, A.; Godfrey, K.; Lopez-Jaramillo, P.; Hornstra, G. Maternal and neonatal essential fatty acid status in phospholipids: An international comparative study. Eur. J. Clin. Nutr. 1997, 51, 232-242. [CrossRef] [PubMed]

11. Metherel, A.H.; Aristizabal Henao, J.J.; Stark, K.D. EPA and DHA levels in whole blood decrease more rapidly when stored at $-20{ }^{\circ} \mathrm{C}$ as compared with room temperature, 4 and $-75{ }^{\circ} \mathrm{C}$. Lipids 2013, 48, 1079-1091. [CrossRef] [PubMed]

12. Metherel, A.H.; Stark, K.D. Cryopreservation prevents iron-initiated highly unsaturated fatty acid loss during storage of human blood on chromatography paper at $-20^{\circ} \mathrm{C}$. J. Nutr. 2015, 145, 654-660. [CrossRef] [PubMed]

13. Folch, J.; Lees, M.; Sloane Stanley, G.H. A simple method for the isolation and purification of total lipides from animal tissues. J. Biol. Chem. 1957, 226, 497-509. [PubMed]

14. Zhang, J.; Wang, Y.; Meng, L.; Wang, C.; Zhao, W.; Chen, J.; Ghebremeskel, K.; Crawford, M.A. Maternal and neonatal plasma $n-3$ and $n-6$ fatty acids of pregnant women and neonates from three regions of China with contrasting dietary patterns. Asia Pac. J. Clin. Nutr. 2009, 18, 377-388. [PubMed]

15. Al, M.D.M.; van Houwelingen, A.C.; Hornstra, G. Relation between birth order and the maternal and neonatal docosahexaenoic acid status. Eur. J. Clin. Nutr. 1997, 51, 548-553. [CrossRef] [PubMed]

16. Koletzko, B.; Larque, E.; Demmelmair, H. Placental transfer of long-chain polyunsaturated fatty acids (LC-PUFA). J. Perinat. Med. 2007, 35 (Suppl. S1), S5-S11. [CrossRef] [PubMed]

17. Stark, K.D.; Beblo, S.; Murthy, M.; Buda-Abela, M.; Janisse, J.; Rockett, H.; Whitty, J.E.; Martier, S.S.; Sokol, R.J.; Hannigan, J.H.; et al. Comparison of bloodstream fatty acid composition from African-American women at gestation, delivery, and postpartum. J. Lipid Res. 2005, 46, 516-525. [CrossRef] [PubMed] 
18. Stark, K.D.; Beblo, S.; Murthy, M.; Whitty, J.E.; Buda-Abela, M.; Janisse, J.; Rockett, H.; Martier, S.S.; Sokol, R.J.; Hannigan, J.H.; et al. Alcohol consumption in pregnant, black women is associated with decreased plasma and erythrocyte docosahexaenoic acid. Alcohol. Clin. Exp. Res. 2005, 29, 130-140. [CrossRef] [PubMed]

19. Wadhwani, N.; Patil, V.; Pisal, H.; Joshi, A.; Mehendale, S.; Gupte, S.; Wagh, G.; Joshi, S. Altered maternal proportions of long chain polyunsaturated fatty acids and their transport leads to disturbed fetal stores in preeclampsia. Prostaglandins Leukot. Essent. Fatty Acids 2014, 91, 21-30. [CrossRef] [PubMed]

20. Enke, U.; Jaudszus, A.; Schleussner, E.; Seyfarth, L.; Jahreis, G.; Kuhnt, K. Fatty acid distribution of cord and maternal blood in human pregnancy: Special focus on individual trans fatty acids and conjugated linoleic acids. Lipids Health Dis. 2011, 10, 247. [CrossRef] [PubMed]

21. Markhus, M.W.; Skotheim, S.; Graff, I.E.; Froyland, L.; Braarud, H.C.; Stormark, K.M.; Malde, M.K. Low omega-3 index in pregnancy is a possible biological risk factor for postpartum depression. PLoS ONE 2013, 8. [CrossRef]

22. Olsen, S.F.; Hansen, H.S.; Sommer, S.; Jensen, B.; Sorensen, T.I.; Secher, N.J.; Zachariassen, P. Gestational age in relation to marine n-3 fatty acids in maternal erythrocytes: A study of women in the Faroe Islands and Denmark. Am. J. Obstet. Gynecol. 1991, 164, 1203-1209. [CrossRef]

23. Rioux, F.M.; Belanger-Plourde, J.; Leblanc, C.P.; Vigneau, F. Relationship between maternal DHA and iron status and infants' cognitive performance. Can. J. Diet. Pract. Res. 2011, 72, 76. [PubMed]

24. Stewart, F.; Rodie, V.A.; Ramsay, J.E.; Greer, I.A.; Freeman, D.J.; Meyer, B.J. Longitudinal assessment of erythrocyte fatty acid composition throughout pregnancy and post partum. Lipids 2007, 42, 335-344. [CrossRef] [PubMed]

25. Young, C.; Hikita, T.; Kaneko, S.; Shimizu, Y.; Hanaka, S.; Abe, T.; Shimasaki, H.; Ikeda, R.; Miyazawa, Y.; Nakajima, A. Fatty acid compositions of colostrum, cord blood, maternal blood and major infant formulas in Japan. Acta Paediatr. Jpn. 1997, 39, 299-304. [CrossRef] [PubMed]

26. Sanjurjo, P.; Matorras, R.; Ingunza, N.; Alonso, M.; Rodriguez-Alarcon, J.; Perteagudo, L. Cross-sectional study of percentual changes in total plasmatic fatty acids during pregnancy. Horm. Metab. Res. 1993, 25, 590-592. [CrossRef] [PubMed]

27. Krasevec, J.M.; Jones, P.J.; Cabrera-Hernandez, A.; Mayer, D.L.; Connor, W.E. Maternal and infant essential fatty acid status in Havana, Cuba. Am. J. Clin. Nutr. 2002, 76, 834-844. [PubMed]

28. Xie, L.; Innis, S.M. Genetic variants of the fads1 fads2 gene cluster are associated with altered (n-6) and (n-3) essential fatty acids in plasma and erythrocyte phospholipids in women during pregnancy and in breast milk during lactation. J. Nutr. 2008, 138, 2222-2228. [CrossRef] [PubMed]

29. Koletzko, B.; Lattka, E.; Zeilinger, S.; Illig, T.; Steer, C. Genetic variants of the fatty acid desaturase gene cluster predict amounts of red blood cell docosahexaenoic and other polyunsaturated fatty acids in pregnant women: Findings from the avon longitudinal study of parents and children. Am. J. Clin. Nutr. 2011, 93, 211-219. [CrossRef] [PubMed]

30. Ghebremeskel, K.; Min, Y.; Crawford, M.A.; Nam, J.H.; Kim, A.; Koo, J.N.; Suzuki, H. Blood fatty acid composition of pregnant and nonpregnant Korean women: Red cells may act as a reservoir of arachidonic acid and docosahexaenoic acid for utilization by the developing fetus. Lipids 2000, 35, 567-574. [CrossRef] [PubMed]

(C) 2015 by the authors; licensee MDPI, Basel, Switzerland. This article is an open access article distributed under the terms and conditions of the Creative Commons by Attribution (CC-BY) license (http://creativecommons.org/licenses/by/4.0/). 